\title{
Reflexões contrapedagógicas: desaprender e incendiar não são coisas que se pode separar ${ }^{1}$
}

\author{
Counter-pedagogical Reflections: Unlearning \\ and Burning Are Not Things That Can Be Separated
}

\author{
Reflexiones contrapedagógicas: desaprender \\ e incendiar no son cosas que se pueden separar
}

Mônica Hoff Gonçalves *

http://dx.doi.org/10.22409/poiesis.2033.41-54

\begin{abstract}
RESUMO: O presente artigo apresenta-se como um conjunto de notas e reflexões sobre as tensões e friç̧ões que envolvem o termo pedagogia, seus usos e sentidos, desde diferentes perspectivas - pedagogias do poder, pedagogias libertadoras - e, principalmente, deslocamentos - contrapedagogias - a partir de uma série de manifestações, performances, ações públicas, pronunciamentos e projetos artísticos levados a cabo, sobretudo, na última década, por artistas, coletivxs, grupxs e diferentes agentes.

PALAVRAS-CHAVE: pedagogias do poder; pedagogias libertadoras; contrapedagogias; episteme própria
\end{abstract}

\footnotetext{
* Mônica Hoff Gonçalves é artista e investigadora. Atualmente cursa doutorado em Processos Artísticos Contemporâneos no PPGAV-UDESC, no qual desenvolve investigação sobre a criação de escolas como prática artística e como metodologias artísticas (não) se convertem em pedagogias instituintes. E-mail: monicahoff@gmail.com. Orcid: https://orcid.org/0000-0001-7376-0762
} 
ABSTRACT: The present article presents itself as a set of notes and reflections on the tensions and frictions that involve the term pedagogy - its uses and meanings -, from different perspectives - pedagogies of power, liberation pedagogies - and displacements - counterpedagogies - from a series of manifestations, performances, public actions, pronouncements and art projects carried on, especially in the last decade, by artists, collectives, groups and different agents.

KEYWORDS: pedagogies of power; pedagogies of liberation; counterpedagogies; own episteme

RESUMEN: El presente artículo se presenta como un conjunto de notas y reflexiones sobre las tensiones y fric-ciones que involucran el término pedagogía, sus usos y sentidos, desde diferentes perspectivas - pe-dagogías del poder, pedagogías liberadoras - y, principalmente, desplazamientos - contrapedagogías a partir de una serie de manifestaciones, performances, acciones públicas, pronunciamientos y pro-yectos artísticos llevados a cabo, sobre todo, en la última década, por artistas, colectivxs, grupxs y diferentes agentes.

PALABRAS CLAVE: pedagogías del poder; pedagogías liberadoras; contrapedagogias; episteme propia

Como citar: GONÇALVES, Mônica Hoff. Reflexões contrapedagógicas: desaprender e incendiar não são coisas que se pode separar. Poiésis, Niterói, v. 20, n. 33, p. 41-54, jan./jun. 2019.

doi: http://dx.doi.org/10.22409/poiesis.2033.41-54

Poiésis, Niterói, v. 20, n. 33, jan./jun. 2019. 


\section{Reflexões contrapedagógicas: desaprender e incendiar não são coisas que se pode separar}

Falar de pedagogia pode ser bastante perigoso. A serviço "do saber", ela tem a poderosa capacidade de atravessar toda a estrutura social construindo discursos, práticas e formas de conhecimento. Trata-se, portanto, de um lugar de poder, e falar de poder é igualmente muito arriscado, não apenas porque há muitas formas de abordá-lo, como bem nos mostraram Hannah Arendt, Michel Foucault, Paulo Freire, Ivan Illich, mas principalmente porque é mais fácil cair na tentativa de inverter sua lógica ao invés de subvertê-la, e toda inversão é de alguma forma a perpetuação do mesmo. Isso se aplica obviamente também à pedagogia. As contrapedagogias são outra coisa. 
A pedagogia da crueldade, por exemplo, é a própria crueldade e a variedade de complexidades que esta noção carrega consigo. A pedagogia do medo é o medo propriamente dito. A pedagogia do controle é o controle. A pedagogia das instituições são as próprias instituições, em seus enunciados, visibilidades, poderes e saberes. A pedagogia da ordem é, assim, a própria construção da ordem. A pedagogia da opressão é a opressão ela mesma. A pedagogia da violência é o aparato de violência construído para que possamos reconhecê-la como tal. A pedagogia do progresso, por sua vez, é cruelmente civilizatória, chegou nestas terras há 500 anos, branca, vestida, de boa família e devastadora. Assim nos "ensinaram" os das caravelas; assim seguem atuando as pedagogias do poder em 2019. As contrapedagogias são outra coisa.

A pedagogia do oprimido ${ }^{2}$ é uma pedagogia que existe a partir do sujeito e de sua luta diária contra as forças opressoras. A pedagogia da autonomia, aliada a esta, pressupõe o respeito ao que é próprio a este sujeito, ao seu acervo de conhecimentos empíricos, à sua individualidade. A pedagogia da pergunta é a pedagogia que se encharca de vida para existir em potência como questionamento do mundo todos os dias. A pedagogia da esperança, por sua vez, é uma pedagogia que aspira mais do que espera, utópica e desejante como as demais, ela se faz vida na renovação da luta diária. Ainda há a pedagogia da marcha, reunião de todos estes questionamentos existindo coletivamente como resistência. Por fim, a pedagogia como prática da liberdade, a soma de todas as anteriores, aquela que só existe na transformação do outro enquanto transformação de si mesma, o que não é pouco. As contrapedagogias, no entanto, são ainda outra coisa.

Quando, em 2016, secundaristas de todo o Brasil ocuparam suas escolas em defesa da educação pública, mobilizando famílias, vizinhos, amigos, professores e parte da sociedade brasileira promovendo assembléias e debates públicos, reformando, limpando e gerindo suas escolas, debatendo e alterando currículos, negociando com os governantes e virando o jogo político da reforma do ensino médio proposta pelos governos estaduais e federal à época, aquele foi um dos maiores movimentos contrapedagógicos que o país já viu.

Poiésis, Niterói, v. 20, n. 33, jan./jun. 2019. 
Quando Alessandra Korap Munduruku³ ${ }^{3}$ em 2019, toma a palavra em audiência pública da Câmara dos Deputados, em Brasília, e assume seu lugar de fala não-branco, nãoocidental, não-cartesiano, não-patriarcal, para defender seu povo, sua terra, sua história e seu direito à existência fora das pedagogias do patriarcado capitalista de supremacia branca, isso é contrapedagogia.

Quando, em 1987, Ailton Krenak, em seu pronunciamento ${ }^{4}$ em defesa da Emenda Popular da União das Nações Indígenas junto à Assembleia Constituinte em Brasília pintou o rosto com jenipapo enquanto defendia a existência, a cultura, o jeito de pensar e de viver dos povos indígenas no Brasil, seu cuidado com a natureza, seu respeito à vida e seu comprometimento com cada pedaço de terra deste país, isso é contrapedagogia.

Quando, em 2019, um grupo de mulheres camponesas se reúne por três dias no centro de artes de uma universidade pública brasileira em defesa da reforma agrária para discutir publicamente sobre a agricultura camponesa, a produção agroecológica dos alimentos, a importância da demarcação das terras indígenas e a violência que sofrem como mulheres, isso é contrapedagogia.

Quando Conceição Evaristo escreve "A gente combinamos de não morrer" em um de seus contos de Olhos $D^{\prime A ́ g u a}{ }^{5}$, a relação entre ficção e realidade se mistura e, se por um lado, a autora encharca a ficção de uma realidade que lhe atravessa por completo, por outro ela afirma - em uma desobediência semântica e, portanto, política - que há um pacto de luta e resistência contra esta realidade. E isso é contrapedagogia.

Quando Erika Malunguinho, mulher trans, negra, artista e, hoje, deputada estadual pelo estado de São Paulo cria a Aparelha Luzia ${ }^{6}$, um quilombo urbano, no meio da babilônia artístico-capitalista de supremacia branca que é a capital paulistana, isso é contrapedagogia.

Quando Mariana Berta, na apresentação pública de sua monografia de graduação em arte, apresenta $\mathrm{SAGU}^{7}$, um trabalho que se constrói em corpo, texto e linguagem a partir de sua vivência camponesa, não repeitando regras acadêmicas, tampouco normas do 
português dito culto e questionando a distância entre prática e teoria nas escolas de arte, assim como os parâmetros do que pode ou não ser considerado conhecimento, isso não é crítica institucional, é contrapedagogia.

Quando Carmem Silva ${ }^{8}$, em 2016, ocupa com 130 famílias um prédio abandonado há mais de três décadas no centro de São Paulo, organizando e garantindo moradia para cerca de 450 pessoas (sem, contudo, garantir a sua) criando modos outros de convivência, trabalho e colaboração, construindo uma biblioteca comunitária, uma brinquedoteca, uma marcenaria, entre outros espaços comuns, isso é contrapedagogia.

Quando Marielle Franco $^{9}$, brutalmente assassinada no dia 14 de março de 2018 pela negligência do estado, em seu último pronunciamento realizado em sessão da Câmara de Veradores do Rio de Janeiro alguns meses antes diz: "Não serei interrompida! Não aturo o interrompimento dos vereadores desta casa, não aturarei o cidadão que veio aqui e não sabe ouvir a posição de uma mulher eleita!", ela não estava defendendo naquele momento apenas o exercício de um direito, mas encarnando uma luta da qual não era alheia, a luta diária que "nasce no asfalto", como mencionara, que lhe cruzava o corpo, a vida e a existência pelos direitos humanos daquelas e daqueles que não raramente não são considerados humanos pela sociedade brasileira. Isso, em um país racista, colonialista, escravocrata e misógino como o Brasil, também pode ser chamado de contrapedagogia.

Quando a artista peruana Daniela Ortiz, vivendo na Espanha há muitos anos, se debruça sobre as leis de imigração e de custódia de crianças e expõe em seus trabalhos o racismo estrutural do estado colonial espanhol com imigrantes e pessoas racializadas, isso é contrapedagogia. Quando Ortiz escreve, publica e apresenta em oficinas para famílias e crianças o $A B C$ de la Europa Racista ${ }^{10}$, isso é novamente contrapedagogia. Quando Daniela, em palestra pública no Creative Time Summit Miami ${ }^{11}$, faz uma análise do racismo europeu ao apresentar imagens da celebração feita na Espanha com relação ao dia 12 de outubro como festa nacional, que nos Estados Unidos é conhecido como Dia de Colombo ou Dia da Hispanidade, e no México, Argentina e em outros países latino-

Poiésis, Niterói, v. 20, n. 33, jan./jun. 2019. 
americanos como Día de la Raza, enquanto cuida e amamenta seu filho Inti que, ao nascer foi considerado apátrida pelo estado espanhol por, embora ter nascido na Espanha, não ser filho de um "ventre espanhol", declarando desde sua condição de existência e seu lugar de resistência, portanto, o imperialismo e a lógica colonialista como um perpetuo contínuo há mais de 500 anos, isso é duplamente contrapedagogia.

Quando Lia García ${ }^{12}$, pedagoga e artista mexicana, realiza Mis XXy años, ação que o mundo da arte vai entender como performance, o feminismo branco como uma afronta ${ }^{13}$ e que Lia vai chamar de encontro - que marca ao mesmo tempo o seu processo de transição como mulher trans e de dor e cura frente às imposições normativas e violências sofridas ao longo de sua vida, isso, sobretudo, é contrapedagogia. Quando Lia García organiza esta "fiesta" dentro do Centro de Residências Artísticas do Matadero Madrid e ela é aberta apenas a pessoas imigrantes e racializadas de Madri, isto é, a pessoas que vivem em situação de subalternidade, opressão e violência naquele contexto, desestabilizando e provocando, assim, uma situação de desconforto na comunidade eurobranca local, ou na melhor das hipóteses fazendo-lhes pensar sobre o que a levou a esta decisão, isso é uma vez mais contrapedagogia.

Quando o artista mexicano Jhoel Zempoalteca cria e encarna a Nossa Senhora da Transmissão ${ }^{14}$ expondo os discursos neoliberais que enunciam, o que pode ou não ser considerado saúde, a ficção da autossuficiência, a heteronormatividade como parâmetro de controle dos corpos e das relações, e as noções de enfermidade e de corpo enfermo como construções estrategicamente excludentes e discriminatórias, isso é contrapedagogia.

Quando MC Carol aceita o convite da Brown University, uma das mais antigas e respeitadas universidades dos Estados Unidos, para dar uma palestra sobre a situação política e social do Brasil e faz sua fala entoando um funk feminista, ela não está palestrando sobre uma dada conjuntura, está encarnando tal situação a partir da própria vida, e isso é contrapedagogia. 
Quando Daniel Sepúlveda cria o Círculo Permanente de Estudos Independentes Menos Foucault Más Shakira ${ }^{15}$ na Cidade do México para analisar coletivamente produtos culturais a partir de teorias feministas latino-americanas e do pensamento anti-colonial, chamando de antemão nossa atenção para o fato de que a teorização sobre o biopoder (Foucault) não é o biopoder na prática (Shakira), isso já é contrapedagogia. Quando Sepúlveda, convidado a fazer uma residência no Museo Reina Sofía em Madri, ocupa o espaço de seu workshop para pintar faixas que questionam aquele lugar, seus enunciados e suas práticas e as coloca em uma das paredes de uma das salas onde está sendo apresentado Hospício de Utopías Fallidas, exposição retrospectiva de Luis Camnitzer, artista uruguaio conhecido por questionar e desestabilizar a relação de subserviência entre arte e educação, isso é contrapedagogia ao quadrado.

Quando o Coletivo Ayllu ${ }^{16}$, grupo colaborativo de investigação e de ação artístico-política formado em Madri por agentes migrantes, racializadxs e dissidentes sexuais e de gênero provenientes das ex-colônias españolas realiza a exposição Devuélvannos el oro ${ }^{17}$, ele não está apenas apresentando o resultado de uma residência realizada no Centro de Residências Artísticas do Matadero Madrid, mas convocando de maneira incisiva e direta o espectador e a comunidade local a que pense e reflita sobre o que aquele título em tom imperativo está dizendo. A partir da apresentação de documentos de conquistadores e das crônicas coloniais, da documentação de ações e performances anti-coloniais realizadas dentro de museus locais, e com uma recepção que incluía a distribuição de moedas de ouro (feitas de chocolate), Ayllu convidou o público a ingerir e digerir o saque colonial, de maneira viva e crítica, e isso é contrapedagogia. Quando ainda Ayllu propõe o P.O.P.S. (Programa Orientado a Práticas Subalternas), como parte de sua residência no Matadero, aberto apenas a pessoas imigrantes, sexo-dissidentes e racializadas, para analisar justamente "fenômenos como a imigração e as dissidências sexuais e promover a produção de conhecimento crítico coletivo desde perspectivas (in)consicentes de raça, sexo e classe como ferramentas de câmbio social e prática libertadora"18, isso é mais do que nunca contrapedagogia.

Poiésis, Niterói, v. 20, n. 33, jan./jun. 2019. 
Quando Jota Mombaça ${ }^{19}$ defende que o pós-colonialismo não existe, que se trata de uma construção politicamente ambígua e desmobilizadora, ela está nos dizendo não somente que há neste termo uma mentira confortável e alienada construída a partir de uma ideia de que o colonialismo é um acontecimento histórico vivido há 500 anos que chegou ao seu fim após os processos de independência levados a cabo pelas ex-colônias no século XVIII, como principalmente que a "bio-lência" é um dos maiores produtos de um processo de colonização que nunca efetivamente acabou, sendo constantemente atualizado em seus modos de dominação e na "sofisticação e rearticulação do poder colonial" em tempos contemporâneos, isso é contrapedagogia racista e colonialista.

Quando bell hooks, em ensinando a transgredir: a educação como prática da liberdade ${ }^{20}$, relata que, ao viver uma infância difícil sem nunca sentir que tivesse um lar, encontrou na teorização, isto é, em entender o que estava acontecendo, o seu refúgio, ao mesmo tempo um lugar de cura e onde ela podia imaginar futuros possíveis. De acordo com a autora, "quando a nossa experiência vivida na teorização está fundamentalmente ligada a processos de autorrecuperação, de libertação coletiva, não existe brecha entre a teoria e a prática"; pelo contrário, essa experiência evidencia ainda mais "o elo entre as duas um processo que, em última análise, é recíproco, onde uma capacita [e fortalece] a outra". Nesse sentido, hooks nos alerta: "nenhuma teoria que não possa ser comunicada numa conversa cotidiana pode ser usada para educar". Quando sua teoria, ao imaginar futuros possíveis, parte de sua vida cotidiana vivida e se materializa em sua prática no presente instaurando lugares de pensamento crítico e debate que até então não existiam ou eram considerados no seu contexto de atuação - no caso o acadêmico -, isso é contrapedagogia.

Quando Rita Segato ${ }^{21}$ descreve e reflete sobre as pedagogias do poder para, desde sua condição como pesquisadora, mas também, senão sobretudo, como mulher, propor as contrapedagogias da crueldade - e com isso a construção de um projeto histórico dos vínculos, e não mais das coisas como propõe o sistema patriarcal -, não é apenas desde uma análise antropológica que ela o faz, mas do encontro de suas investigações com as vivências, dores e violências vividas como mulher. E isso é, sobretudo, contrapedagogia. 
Quando Silvia Rivera Cusicanqui ${ }^{22}$ elege e defende a sociologia em sua dimensão criativa, a "busca por uma episteme própria" e a oralidade como um lugar que potencializa à experiência vivida estimulando, com isso, a insurgência de outras formas de cognição, isso é contrapedagogia.

Quando Elza Soares diz "Deus é muito bom comigo, foi muito fiel comigo a vida toda. Por isso que ele é mulher"23, isso é a contrapedagogia em seu esplendor. Quando ainda Elza, a mulher do fim do mundo, recebe em 2019, da Universidade Federal do Rio Grande do Sul, o título de doutora honoris causa, o primeiro conferido por esta universidade no contexto da música, isso não apenas é fruto de uma contrapedagogia levada ao extremo da vida por Elza, como é um sinal de que (des)aprender e incendiar são ações fundamentais para caminhar em tempos tão endurecidos como os de hoje, e não são coisas que se pode separar! Exu nas escolas! ${ }^{24}$

Quando mais de um milhão de pessoas saem às ruas do Brasil em 15 de maio de $2019^{25}$, menos de cinco meses depois da posse do novo governo, para reivindicar direitos e defender a educação pública no país, não estou certa de que isso seja contrapedagogia, mas é imenso! Exu nas escolas, por favor!

Se, ainda neste movimento, caminharmos um pouco para atrás e tomarmos como referência e mirada as pedagogias críticas libertadoras de Paulo Freire e Ivan Illich $^{26}$, que defendiam, respectivamente, a desescolarização da escola e da sociedade, é possível que encontremos alguns vínculos com o que estamos chamando contrapedagogia, a ponto de, se não de todo pelo menos em parte, questionarmo-nos se as contrapedagogias não seriam a exaltação - a ocorrência na prática e em seu grau máximo - das pedagogias libertadoras propostas pelos dois pensadores nos anos 1960 e, portanto, sua transmutação também. A principal aproximação entre elas, a mais visível talvez, é o fato de que ambas buscam revisar as pedagogias do poder, propondo, com isso, um questionamento das normas que sustentam e conferem sentido a tais pedagogias.

Poiésis, Niterói, v. 20, n. 33, jan./jun. 2019. 
No entanto, se as pedagogias libertadoras o fazem como programa, desejo ou proposição a um, dois ou três milhões, as contrapedagogias são a sua realização na prática, no chão do presente, no calor dos corpos, das lutas e das dores que dão vida a estes corpos. São a materialização dos inéditos viáveis de Freire e a sua desobediência também. São uma outra pedagogia da esperança - menos utópica e mais tópica -, levada a cabo por outros sentidos de vida que desobedecem não apenas as pedagogias do poder como, principalmente, o sentido de pedagogia. E isso não é pouco.

Diferente das pedagogias, as contrapedagogias não se estruturam como respostas palatáveis ou mesmo reconhecíveis às estruturas de poder, tampouco se preocupam em ensinar novas formas de aprender; se tratam, pois, de processos vivos, individuais e coletivos, de desaprendizagem do mundo e do conjunto de saberes, normas e maneiras que este mundo considerou que deveria ser aprendido até então. Elas não nos estão falando, portanto, somente do direito de existir como cidadão, mas do direito à existência fora das normativas determinadas pelo estado e pela ordem social que determinam o que é um cidadão.

Desviantes, descolocadas, dissidentes, desobedientes e, portanto, desconhecidas para as forças colonizadoras, opressivas, racistas, misóginas do patriarcado capitalista de supremacia branca, as contrapedagogias não são teorias que se pode tercerizar em práticas e modelos reprodutíveis; não são "civilizadas" nem civilizatórias pois não acreditam no conceito imposto de civilização; não são salvadoras nem pedem permissão; não se adaptam nem querem se adaptar; são elas as pedagogias (enquanto episteme própria, tal qual defende Cusicanqui) daquelas e daqueles que já não se deixam mais oprimir; são pedagogias cuja existência está diretamente relacionada a sua capacidade de desobedecer à própria noção de pedagogia. Por isso nos custa tanto entender, porque demandam que mudemos a nossa lógica de entendimento. Não são jardins, são florestas! 


\title{
Notas
}

\begin{abstract}
${ }^{1}$ Este texto surge como uma reflexão a partir de notas, conversas, leituras e processos de escuta que tiveram lugar antes, durante e após a realização da oficina Anotaciones Contra-pedagógicas: desaprender e incendiar, que ministramos Daniel Sepúlveda, artista e investigador mexicano e idealizador do CIPEI Menos Foucault Más Shakira, e eu, à convite do Projeto FelipaManuela no Centro de Residências Artísticas do Matadero Madrid, no dia 25 de janeiro de 2019.
\end{abstract}

${ }^{2}$ Este parágrafo faz alusão à proposta de Paulo Freire de que a Pedagogia da Esperança fosse um reencontro com a Pedagogia do Oprimido. Seguindo seu exercício, o que se propõe aqui é um encontro entre pedagogias freirianas - da pedagogia do oprimido às pedagogia da autonomia, da esperança, da pergunta e como prática da liberdade - a fim de pensar as relações entre elas e poder e, com isso, visualizar as conexões, fricções e campo de reflexões que estabelecem com o que hoje podemos chamar contrapedagogias. Ver FREIRE, Paulo. Pedagogia da Esperança. Um reencontro com a pedagogia do oprimido. São Paulo: Paz e Terra, 2011.

${ }^{3}$ Fala feita em abril de 2019, disponível em https: / /www.youtube.com/watch?v=DDU_vC6mSgY.

${ }^{4} \mathrm{O}$ pronunciamento de Ailton Krenak está disponível em https://www.youtube.com/watch?v=TYICwl6HAKQ\&fe ature=youtu.be.

${ }^{5}$ EVARISTO, Conceição. A gente combinamos de não morrer. In: Olhos d'água. Rio de Janeiro: Pallas / Fundação Biblioteca Nacional, 2016, p. 99.

${ }^{6}$ Ver Espaço cultural fomenta debates políticos voltados para a população negra, por Beatriz Sanz (El País). Disponível em https://www.geledes.org.br/aparelha-luzia-o-quilombo-urbano-de-sao-paulo/.

${ }^{7}$ BERTA, Mariana. Sagu. Monografia apresentada para conclusão do curso de Artes Visuais, UDESC, 2017.

${ }^{8}$ Fala de Carmen Silva sobre a Ocupação 9 de Julho e a luta diária do MSTC por moradia. Disponível em https: //jornalistaslivres.org/ocupacao-9-de-julho-para-eleicao-de-bolsonaro/.

${ }^{9}$ Ver FRANCO, Marielle. UPP - A redução da favela em três letras: uma análise da política de segurança pública do estado do Rio de Janeiro. São Paulo: n-1 edições, 2018.

10 ORTIZ, Daniela. El ABC de la Europa Racista. Cidade do México: Pensare Cartonera, 2017. Disponível em https://pensarecartoneras.wordpress.com/2018/02/27/abc-de-la-europa-racista-daniela-ortiz-pdf/.

${ }^{11}$ Registro videográfico disponível em https://www.youtube.com/watch?v=FHO5CnBPZ2k.

Poiésis, Niterói, v. 20, n. 33, jan./jun. 2019. 
${ }^{12}$ Registro videográfico de uma das apresentações públicas de Mis XXy años, disponível em https://sureandoelcuerpo.wordpress.com/2018/08/15/lia-garcia-la-novia-sirena-desmenuzar-la-memoria-archivo-afectivo-mis-xxyanos/.

${ }^{13}$ Conforme comentou a artista em workshop ministrado junto ao Programa Orientado a Práticas Subalternas (POPS) levado a cabo pelo Colectivo Ayllu no Centro de Residências do Matadero Madrid, por ser uma festa de quinze anos, bastante tradicional em muitos países da América Latina e que marca o momento na cultura patriarcal em que as famílias apresentam/entregam a filha à sociedade, exibindo-a como uma mulher a ser despojada, Mis XXy años, não raramente é interpretado desde o feminismo radical como uma afronta à luta feminista. No entanto, o que a ação de Lia provoca, em realidade, é uma torção na própria estrutura e lógica deste acontecimento quando ocupa este lugar e esta celebração desde a sua história e seu corpo.

${ }^{14}$ Nuestra Señora de la Transmisión é uma performance do artista mexicano Jhoel Zempoalteca, realizada no Centro Cultural Border, na Cidade do México, em 2018. Parte de sua documentação, como o texto mencionado e um registro em imagem, pode ser acessado na publicação CORRERIO. Org. Leo Felipe e Jorge Bucksdricker. Florianópolis, 2019.

${ }^{15}$ Link do projeto disponível em https://foucaultmasshakira.wixsite.com/cipei.

${ }^{16}$ Link do blog do Ayllu disponível em http://migrantestransgresorxs.blogspot.com/.

${ }^{17}$ Sobre Devuélvannos el oro, ver em http://desde-elmargen.net/devuelvannos-el-oro-una-introduccion/.

${ }^{18}$ Texto de apresentação do Programa. Disponível em http://www.mataderomadrid.org/ficha/9580/p.o.p.s. programa-orientado-a-practicas-subalternas.html.

19 Bio-lencia descolonial, matar la academia. Entrevista com Jota Mombaça. Disponível em https://anarcopunk. org/v1/2017/07/bio-lencia-descolonial-matar-la-academia-entrevista-a-jota-mombaca/.

${ }^{20}$ hooks, bell. Ensinando a transgredir: a educação como prática da liberdade. São Paulo: Martins Fontes, 2013, p. $85-86$

${ }^{21}$ SEGATO, Rita. Contra-pedagogías de la crueldad. Buenos Aires: Prometeo Libros, 2018. As três aulas que originaram o livro estão disponíveis em (aula 1) https: //www.youtube.com/watch?v=17ijWDlok2g; (aula 2) em https: //www.youtube.com/watch?v=f92n-GSJDso; (aula 3) em https://www.youtube.com/watch?v=oTmr7UORWAM.

${ }^{22}$ Ver CUSICANQUI, Silvia Rivera. Un mundo ch'ixi es posible. Ensayos desde un presente en crisis. Buenos Aires, Tinta Limón, 2018.

${ }^{23}$ Entrevista com Elza Soares publicada em 21/05/2018, disponível em https://gauchazh.clicrbs.com.br/culturae-lazer/musica/noticia/2018/05/deus-e-muito-bom-comigo-foi-muito-fiel-comigo-a-vida-toda-por-isso-que-ele-emulher-diz-elza-soares-cjhggzwk306te01 paliykv2lx.html. 
24 “Exu nas escolas", composição de Kiko Dinucci e Edgar, é uma das músicas que integra o disco Deus é mulher, lançado por Elza Soares em 2018. A canção é uma poderosa crítica social ao estado segregacionista e escravocrata brasileiro. Está disponível em https: //www.youtube.com/watch?v=NmDsmHtOgyw.

${ }^{25}$ Balanço das manifestações em defesa da educação e da universidade pública realizadas em mais de 140 cidades brasileiras no dia 15 de maio de 2019. Disponível em https://medium.com/@MidiaNINJA/levante-hist\%C3\%B3ricomais-de-200-cidades-se-mobilizam-contra-cortes-na-educa\%C3\%A7\%C3\%A3o-1c778627af21?fbclid=IwAR3z5cFkS4sm LISp4dQ0reH9NU7PI9j1juHXtAD48FwLhCw6sVz41KSKP1I.

${ }^{26}$ Ver ILLICH, Ivan. Sociedade sem escolas. Petrópolis: Vozes, 1985. 